\title{
A pergunta como espaço de inscrição identitária
}

\author{
Gesualda dos Santos Rasia ${ }^{1}$
}

\begin{abstract}
This paper approaches the operation of the questioning structure, from a discursive perspective based on Michel Pecheux, which engages with the historical-cultural field of studies. Thus, the study analyses, in the scope of the biblical discursivity, the report of the hearing of Jesus Christ by Poncio Pilatos, moments before the crucifixion, owing to the singularity and the representativeness of the way this hearing is built in such context. In the question-answer architecture, we have the materialization of the political dissent by means of silence and ambiguities, i.e. strategies that build the identity constitution by crossing the ties of economy and power. The question that drives us is to verify how the queries, the realization of the language in which the non-transparency of the statement is potencialized, are established as place to capture the subject while position, and how the answer at the same time multifacets and circumscribes this position.
\end{abstract}

Keywords: question; discursive operation; political-identity registry.

Resumo: Este estudo investiga a estrutura interrogativa a partir de uma perspectiva discursiva embasada na obra de Michel Pêcheux, que se inscreve nos domínios dos estudos sócio-culturais. Assim, o estudo analisa, no âmbito da discursividade bíblica, a narrativa da escuta de Jesus Cristo por Poncio Pilatos, momentos antes da crucificação, buscando a singularidade e a representatividade da forma como a escuta é construída neste contexto. $\mathrm{Na}$ arquitetura das perguntas-respostas temos a materialização da discordância política por meio do silêncio e de ambigüidades, isto é, estratégias de constituição de identidade obtidas pelo cruzamento de laços entre economia e política. A questão que nos conduz é a verificação de como as perguntas, o uso da linguagem em que a não-transparência do enunciado é potencializada são lugares para capturar o sujeito como uma posição, e como a resposta multifaceta e circunscreve, ao mesmo tempo, esta posição.

Palavras-chave: Pergunta: Operação discursiva; registro de identidade política

1 Docente dos Cursos de Graduação e Pós-Graduação em Letras da Universidade Federal do Paraná. 
Este estudo coloca em cena questões atinentes ao funcionamento da estrutura interrogativa, a partir de uma perspectiva discursiva com filiação em Michel Pêcheux, em diálogo com estudos do campo histórico-cultural. Concebida, no âmbito da retórica clássica, como recurso estilístico, com vistas à exposição de um determinado ponto de vista, na abordagem gramatical a interrogação foi reduzida à tomada enquanto estrutura sintática, excetuando-se alguns espaços da vertente histórica, que levou em conta, ainda que de modo lateral, a dimensão do dizer. A investigação ora proposta visa analisar a pergunta, em diferentes formas de realização, como espaço de inscrição/constituição identitária dos sujeitos que interrogam e dos sujeitos que respondem, procurando compreender como se dão os jogos de força na constituição do par pergunta-resposta e como tais embates circunscrevem politicamente os lugares de dizer. Para tanto, o estudo analisa, no âmbito da discursividade bíblica, o relato do interrogatório de Pôncio Pilatos a Jesus Cristo, momentos antes do episódio da crucificação, devido à peculiaridade e representatividade do modo como se constrói a inquirição nesse quadro. $\mathrm{Na}$ arquitetura pergunta-resposta materializa-se o dissenso político, via silêncios e ambiguidades, estratégias essas que tecem a constituição identitária, pelo atravessamento dos laços de poder e econômicos. A questão que nos toca, então, é verificar como a pergunta, realização de linguagem em que se potencializa a não transparência do dizer, se estabelece enquanto lugar de captura do sujeito enquanto posição, e como a resposta multifaceta e ao mesmo tempo circunscreve essa posição.

\title{
A narrativa bíblica enquanto discursividade
}

A narrativa bíblica é trazida, aqui, como discurso fundador, no sentido definido por Orlandi (1993, p. 13) como "aquele que permite a fundação de sentidos onde outros sentidos já se instalaram”. Trata-se de um discurso que se articula significativamente com um campo de memória, tornando-a passível de outros sentidos, pois

\begin{abstract}
Cria tradição de sentidos, projetando-se para a frente e para trás, trazendo o novo para o efeito do permanente. Instala-se irrevogavelmente. É talvez esse efeito que o identifica como fundador: a eficácia em produzir o efeito do novo que se arraiga no entanto na memória permanente (sem limite). Produz desse modo o efeito do familiar, do evidente, do que só pode ser assim (ORLANDI, 1993, p. 13-14).
\end{abstract}

O discurso bíblico funda o cristianismo, com sua multiplicidade espectral de posições e filiações. A figura de Jesus Cristo, judeu, é nodal nesse desenho. Ao lado de alguns pontos de convergência no que se lê acerca de sua representatividade, coabitam leituras outras e por vezes até divergentes, as quais fundam religiões e denominações como sítios de significância.

Orlandi (1993) aborda o discurso fundador como fornecedor de pistas acerca do funcionamento de questões identitárias em um país, a partir da dimensão do imaginário coletivo, e faz valer a referida noção para refletir acerca de como se constituiu a identidade brasileira no processo colonizatório. No caso do discurso bíblico como fundador, a questão identitária e a da nacionalidade são de muita relevância. Pautado e permeado pela tradição e memória greco-judaica, o discurso bíblico faz emergir pontos de encontro e de distanciamento entre esses dois lugares de sentido. No caso em tela, essencialmente no que ambos convocam em termos religiosos e políticos, conforme aponta a análise ora proposta.

Vale dizer que, neste estudo, a cada vez que nos referimos ao personagem Jesus, estamos fazendo-o na perspectiva de considerá-lo enquanto sujeito de uma discursividade. 
Esta resulta do efeito de sentido do modo como se estabeleceu historicamente esse discurso: ele diz de si próprio a partir da palavra do outro, ao mesmo tempo em que a palavra do outro cristaliza-se, no decurso do tempo, como relato das enunciações do próprio Jesus. Enunciações, portanto, que jogam com o lugar da autoria, tecem o ponto de encontro entre a tradição oral e a escrita e que são carregadas de uma memória histórica, essencialmente aquela relacionada à narratividade veterotestamentária.

O estudo não adentra de modo direto a exploração desse viés, contudo, os lugares de memória do Antigo Testamento (AT) estão presentes, o tempo todo, e de modo constitutivo, no recorte em tela. A questão de fundo acerca das controvérsias acerca de quem era Jesus, e sua consequente crucificação, gira em torno dos significados políticos e religiosos de sua figura, enquanto confirmação ou não das profecias presentes no AT. Segundo Johnson (2011, p. 105),

Nem os judeus, nem os samaritanos tinham certeza se o Messias era um líder secular ou espiritual, ou um pouco de ambos. Os saduceus o viam como outro Davi que iria restaurar o grande reino judeu que florescera mil anos antes. Os fariseus o viam como um sumo sacerdote teocrático que faria do Templo a sede do governo.

Certo é que, fosse pelo viés político ou pelo religioso, ou pelo encontro de ambos, estava em pauta, e não de modo desvinculado, a questão identitária. Judeus, fariseus, saduceus e samaritanos compunham diferentes segmentos dentro do judaísmo, divididos por critérios étnicos, relacionados às suas crenças e por seus diferentes modos de organização política e de como faziam ou não alianças com o Império romano².

É preciso levar em conta, ainda, o fato de que a narratividade bíblica estabeleceu-se enquanto tal a partir de relatos da tradição oral, de diferentes fontes, os quais foram compilados e vertidos para a forma escrita provavelmente entre os anos 60-95 d.C, conforme informações contidas na introdução de cada evangelho ${ }^{3}$. Esse aspecto peculiar de constituição tem implicações relevantes para o estabelecimento enquanto discursividade, tendo em vista variáveis tais como: a) trata-se de diferentes testemunhos relatando os mesmos fatos, com peculiaridades de ponto de vista, posições assumidas. Trata-se do efeito parafrástico produzido a partir de repetições/variações em torno do mesmo; b) a autoria dos Evangelhos, como dos demais livros tem, em sua maioria, atribuições historicamente construídas a partir de indícios fornecidos pelos próprios textos, sem, contudo, haver certificação exata. Trata-se, em todos os casos, de efeito de autoria enquanto assinatura de responsabilização; c) os vestígios da oralidade marcam presença em um texto que historicamente estabeleceu-se como sendo de linguagem elitizada, atestando, com isso, a

\footnotetext{
2 Dentre os partidos destacamos alguns que seguem, descritos por Dockery (2001): os fariseus compunham o partido mais popular na época de Jesus. Acreditavam que as regras de pureza para os sacerdotes em serviço no templo deveriam ser estendidas a todos os aspectos da vida, daí sua ênfase na pureza ritual. Já os saduceus pertenciam ao partido dos sacerdotes. Sua ênfase estava na dedicação ao templo e sua preservação. Para concretizar isso, cooperavam com as autoridades romanas e eram mais abertos às suas influências culturais do que os fariseus. Os samaritanos, por sua vez, não se consideram judeus, mas descendentes dos antigos habitantes do antigo reino de Israel (ou reino da Samaria). São considerados, pelos judeus ortodoxos como descendentes de populações estrangeiras, que adotaram uma versão adulterada da religião hebraica; e, como tal, recusam-se a reconhecê-los como judeus ou até mesmo como descendentes dos antigos israelitas. Contudo, o Estado de Israel reconhece-os como judeus.

3 Existem diferentes hipóteses acerca da passagem da tradição oral para a escrita no registro dos evangelhos. Uma delas, constante em (DOCKERY, 2001), afirma que apenas um 'evangelho oral' estaria por trás dos evangelhos, tendo sido transmitido 'de boca em boca' antes do registro escrito.
} 


\section{Conexão Letras}

heterogeneidade constitutiva da linguagem ${ }^{4}$; d) a passagem de discurso oral para discurso escrito concorre para a circunscrição do dizer em uma ordem de verdade, aspecto esse que terá implicação direta na análise da dimensão do boato na cena da inquirição.

\section{As condições históricas de produção da inquirição.}

Jesus Cristo, figura universal, ao menos no contexto ocidental, foi o precursor de uma discursividade que fundou um paradigma religioso tributário ao seu nome: o cristianismo. Colocado como verdade, a qual é enunciada mais como personificação do que como um conjunto de dogmas ${ }^{5}$, esse discurso configurou-se controverso desde sua fundação. Controvérsias essas nas quais o próprio Cristo investiu, em diversos momentos, por deixá-las em um campo de ambiguidade. E, contemporaneamente, a multiplicidade de crenças, religiões e seitas corroboram o discurso bíblico como lugar, por excelência, aberto à interpretação.

Remetendo-nos à idade adulta de Jesus, na etapa final de seu ministério, importa adentrar, ainda que brevemente, o quadro político-religioso da época, no intuito de delinear as condições de produção em que se insere o quadro da inquirição de Jesus, objeto de análise deste estudo.

Vale dizer, inicialmente, que embora na Roma Antiga fosse estabelecida distinção entre autoridades políticas e religiosas, essas duas dimensões não eram alheias uma à outra, vigorando um forte investimento em manter alinhados os interesses de ambas as esferas e, por conseguinte, as alianças entre seus líderes maiores.

Para tanto, é preciso entender como se dava a divisão dos diferentes poderes e como se configuravam os frágeis laços entre uma posição e outra. Para tanto, baseamo-nos em exposições feitas por Johnson (2011) e Davidson (1997).

Caifás, sumo sacerdote, amigo de Pôncio Pilatos, era caracterizado como manipulador desonesto e habilidoso, o qual apreciava seu poder como líder espiritual da comunidade judaica ortodoxa. Pôncio Pilatos, governador romano da Judéia, de 26 a 37 A.D., uma espécie de procurador, denunciou Jesus porque tinha medo que os líderes religiosos judeus o denunciassem a Roma, onde sua posição era frágil (JONHSON, p.133). Davidson (1997) acrescenta que o cargo de que Pilatos estava investido dependia do prefeito da Síria. Sua residência estava fixada em Cesaréia, mas esteve em Jerusalém para a festa, a fim de controlar qualquer revolta ou distúrbio, visto que naqueles tempos "os sentimentos nacionais se exaltavam" (p. 982 e 1022). Herodes Antipas, principal rei judeu secular da região, não tinha interesse em modificar o status quo de relacionamentos políticos e religiosos.

Diante desses, e pivô de um jogo de interesses pró-manutenção de favorecimento e alianças políticas, estava Jesus, um pregador judeu popular, com grande poder de influência sobre as massas. Johnson (2011) sublinha que o temor era a proliferação de tumultos, caso seus ensinamentos se mostrassem revolucionários.

A postura política e mesmo pessoal de cada um dos líderes comporta sentimentos e atitudes contraditórios. E talvez Pilatos seja, dentre todos, o que se mostra mais vacilan-

4 DAVIDSON (1997) registra a possibilidade de o evangelho de Marcos ter servido como fonte para os relatos posteriores de Mateus e de Lucas, pelo fato de ao primeiro ter sido delegada a tarefa de escrever a pregação oral. E levanta, ainda, a hipótese de que esta tenha sido feita, primeiramente, em aramaico e só mais tarde em grego, em virtude da grande expansão da atividade dos apóstolos. Uma das evidências que conferem sustentação à referida hipótese, segundo o autor, é a presença frequente de "aramaísmos" no texto grego dos Evangelhos.

5 Vide a afirmação de Jesus, a qual tem se constituído como uma das premissas do cristianismo: "Eu sou o caminho, a verdade e a vida" (João 14:6). 
te, ora tendendo a inscrever-se num lugar de outorga de inimputabilidade a Jesus, ora de culpabilidade. Ao perguntar, no vs. 23, do cap. 27 do Evangelho de Mateus 6 , "Que crime ele cometeu?" sinaliza, indiretamente, a possibilidade da inocência de Jesus. E, após a inquirição, composta por uma sequência de perguntas, todas com diferentes retornos da parte de Jesus, Pilatos joga para a multidão a responsabilidade pelo julgamento.

Embora se trate do mesmo episódio, cada versão "escolhe" determinados aspectos em detrimento de outros, consoante o jogo de imagens em tela. No caso de Mateus, vale lembrar que se trata de um judeu escrevendo para seus pares e, neste caso, importa fazer frente ao discurso da responsabilidade/culpabilidade exclusiva de seu povo na crucificação de Cristo, relativizando-o. Somente neste Evangelho consta a cena do "lavar as mãos", da parte de Pilatos, e a declaração, simultânea "estou inocente do sangue deste justo, fique o caso convosco". Em contrapartida, no Evangelho escrito por Marcos, um romano, sobreleva-se a interlocução primeira com os romanos e aí, importa circunscrever a culpabilidade sobre os judeus. Por conta disso, no relato do evangelista, a sentença final proferida por Pilatos é justificada, no versículo 15, do capítulo 15, pelo argumento: "Então, querendo satisfazer a multidão, soltou Barrabás".

Atente-se que, em termos de esquema argumentativo, a conclusão lógica, pode-se dizer, é a mesma:

a)Em Mateus: "Então Pilatos, vendo que nada aproveitava, antes o tumulto crescia, tomando água, lavou as mãos diante da multidão, dizendo: Estou inocente do sangue deste justo." (Mateus 27:24) . $\rightarrow$. a culpa não é de Pilatos, é dos judeus.

b)Em Marcos: Então Pilatos, querendo satisfazer a multidão, soltou-lhe Barrabás e, açoitado Jesus, o entregou para ser crucificado." (Marcos 15:15) $\rightarrow$ a culpa não é de Pilatos, é dos judeus.

Contudo, filigranas do esquema enunciativo nos dão pistas para se chegar ao plano da discursividade. Em Mateus, a narrativa dá voz ao próprio Pilatos, para justificar sua decisão. Já em Marcos, é o narrador que faz o julgamento acerca do que teria movido a decisão de Pilatos. No primeiro caso, por ser o próprio narrador que se auto-inocenta, posição essa fortalecida pelo emblemático "lavar de mãos", fica implicada a acusação externa - é preciso defender-se dos conteúdos possivelmente assertados acerca de sua conduta. Trata-se de fazer demarcar uma posição que faça frente à discursividade que atravessa seu dizer, ou seja, a culpabilidade dos romanos está posta em tela. Já em Marcos, em sendo a voz do narrador que asserta sobre a tentativa de agradar à multidão, e não a voz do próprio Pilatos, deriva-se um juízo de valor sobre o lugar de onde emanou de fato a sentença - da multidão, ainda que Pilatos tenha sido movido por motivos políticos. A atenuação de sua responsabilidade marca-se também pela quantificação do registro de apelos à multidão para que demovesse: um a mais do que em Mateus. Quantificação aparentemente neutra, mas que acaba por demarcar o esforço de Pilatos por demover a turba enraivecida, ratificando a possibilidade de sua crença na inocência de Jesus.

Diante disso, pode-se pensar em um domínio de desestabilização da conclusão lógica, na medida em que jogos de força implicados no esquema enunciativo apontam para o desenho de diferentes posições-sujeito em confronto. E, vale dizer, produzem desestabilizações também no discurso sedimentado no decurso do tempo, acerca da culpabilidade exclusiva do povo judeu na morte de Jesus Cristo. E o esquema anterior poderia ser assim reinterpretado:

6 Todas as referências bíblicas deste estudo foram retiradas da Nova versão internacional. 
a)Em Mateus: Pilatos disse "estou inocente do sangue desse homem”, porque precisava negar uma responsabilidade que também era sua. $\rightarrow$ a culpa está debitada, por implicação, aos romanos, representados por Pilatos, e não aos judeus.

b)Em Marcos: É preciso dizer que a decisão de Pilatos decorreu do "querendo satisfazer à multidão", mas ele tendia a acreditar na inocência de Jesus $\rightarrow$ a culpa fica debitada a Pilatos, portanto, é não aos judeus.

É preciso atentar, ainda, para a dupla perspectiva que tecia a discursividade sobre Jesus enquanto Messias. Se, de um lado, estava sendo dito como o Filho de Deus, redentor da humanidade, de outro, esta figura estava associada à profecia da vinda de um humano descendente do Rei Davi, que iria reconstruir a nação de Israel e restaurar o reino de Davi, o que lhe conferia uma dimensão quase mais política que religiosa, ou produzida a partir da imbricação das duas dimensões. Eagleton (2009) comenta, inclusive, que o fato de a própria noção da palavra messias ser então ininteligível para os não judeus ajuda a entender, talvez, porque, nos relatos, Jesus não afirma inequivocamente ser o Messias:

A tradição messiânica não tem a ver com a redenção da humanidade, mas apenas com a libertação de Israel de seus inimigos políticos. É um tema nacionalista, e essa pode ter sido uma razão para que Jesus dele se conservasse distante (EAGLETON, 2009, p.18).

Davidson (1997) afirma que havia o medo de que Jesus se auto-proclamasse outro rei Davi e se tornasse sacerdote-rei. A discursividade que então se constrói a partir da posição-sujeito Jesus, talvez para fazer frente às implicações dessa ambiguidade, afirma um reinado de ordem espiritual, o qual era apresentado, diante de interpelações das autoridades romanas e judaicas, por meio de estratégias de abertura, tais como perguntas, implícitos, linguagem figurada e ambiguidades. Isso manteve em suspenso a condenação, ao menos por um tempo.

Além disso, se considerada a perspectiva romana, ainda segundo mesmo autor, a afirmação acerca do caráter político, de parte de Jesus, deixaria estes em alerta, já que uma possível militância política judaica apresentava riscos de vir a pôr Israel em pé outra vez.

\section{A configuração do par pergunta-resposta na inquirição}

No relato do Evangelho de João (18:19-24) Jesus é levado primeiramente diante de Anás ${ }^{7}$, sogro e predecessor do sumo sacerdote, onde se configura a dimensão eclesiástica de seu julgamento, de responsabilidade do sinédrio ${ }^{8}$. Ao ser interrogado sobre a doutrina que pregara, ao que Jesus responde com outra pergunta: "Para que me perguntas assim?" , cujo pressuposto sustenta-se pelos argumentos por ele apresentados: a) falei abertamente ao mundo; b) sempre ensinei na sinagoga e no Templo, onde se reúnem todos os judeus, nada falei às escondidas. E após esse arrazoado contra-argumentativo, sugere que perguntem aos discípulos sobre o que ouviram, indicando-os como sabedores de sua doutrina. $\mathrm{O}$ desfecho, é que leva uma bofetada, de parte de um dos guardas do Templo.

O par pergunta-resposta não se constitui, portanto, de modo simétrico, dado que assume a forma pergunta-pergunta. Contudo, o segmento que ocupa, em tese, o lugar da resposta, não deixa de cumprir essa função, pela via da constituição de um domínio de

7 Davidson (1997) afirma que "Anás tinha sido deposto do munus de Sumo sacerdote por Valerius Gratus, procurador romano antes de Pilatos, mas ainda exercia sua influência sorrateiramente."

$8 \mathrm{O}$ sinédrio consistia no tribunal supremos dos judeus, integrado pelos sumo-sacerdotes, os anciãos e os mestres da Lei. Tinha um total de 71 membros, incluindo o seu presidente, cargo que costumava exercer o sumo-sacerdote em exercício. (Bíblia de estudo Almeida, 1999). 
resposta. Ao debitar para terceiros (e não quaisquer) a responsabilidade pelo dizer, Jesus inscreve sua doutrina numa ordem de estabilidade referencial e, de certo modo, legitimidade - haveria seguidores confessos que testificariam ser ele, de fato, o Messias. E não é ele que o afirma. Além disso, o estatuto de sua resposta, que assim acabou se configurando, não pôde, pela estratégia desencadeada, ser sujeito às condições de veridição empírica, mas somente por aquelas desencadeadas pelo raciocínio lógico: "Respondeu-lhe Jesus - Se falei mal, dá testemunho do mal; e, se bem, por que me feres?" (João 18:23).

A essa contraposição, segue-se o silêncio retórico, seguido ou preenchido pela prática da força: Jesus é amarrado e levado a Caifás, o Grande Sacerdote. Johnson (2011) afirma que o esperado por Anás e Caifás, para conferir legitimidade à acusação, era o depoimento de judeus respeitáveis, contudo, o caráter de armação ficou evidente nas acusações dos muitos "contratados". O evangelho de Marcos afirma que "seu testemunho não era coerente" (14:59). O debate implicado nesse cenário e contexto tem como pano de fundo o estatuto das credenciais das diferentes testemunhas.

A manifestação pública da massa que escolheu Jesus para ser crucificado resultou, segundo o autor, de ardil montado pelos sacerdotes. Para sustentar essa posição, ele apresenta o argumento da alta popularidade de Jesus entre o povo, que soa incoerente com a condenação perpetrada pela voz da multidão. Outro argumento é o fato de que os sacerdotes detinham o controle do acesso restrito ao pátio da frente do palácio do governador. "A experiência moderna nos ensina quão facilmente esses protestos oficiais podem ser encenados pelos governantes", afirma o autor (p.124).

$\mathrm{O}$ valor de verdade deriva, neste caso, não do enunciado em si, mas do lugar do dizer. E Jesus antecipa isso, por isso constrói esse lugar, fora de sua elocução, configurando, assim, efeito de verdade espiritual, contudo, paradoxalmente, ausência de verdade jurídica. Uma coisa é ser um líder espiritual, outra, ameaça à hierarquia sacerdotal judaica estabelecida.

Diante de Caifás, onde se desenrola a segunda parte da inquirição, ainda de cunho eclesiástico, acontece diante de Caifás, é apresentada outra configuração na construção retórico-discursiva. Comparem-se os relatos constantes em três dos Evangelhos:

Mateus: Jesus, porém, guardava silêncio. E, insistindo o sumo sacerdote, disse-lhe: Conjuro-te pelo Deus vivo que nos digas se tu és o Cristo, o Filho de Deus.

Disse-lhe Jesus: Tu o disseste; digo-vos, porém, que vereis em breve o Filho do homem assentado à direita do Poder, e vindo sobre as nuvens do céu.

Então o sumo sacerdote rasgou as suas vestes, dizendo: Blasfemou; para que precisamos ainda de testemunhas? Eis que bem ouvistes agora a sua blasfêmia.

Que vos parece? E eles, respondendo, disseram: É réu de morte.

(Mateus 26:63-66).

Marcos: "E levaram Jesus ao sumo sacerdote, e ajuntaram-se todos os principais dos sacerdotes, e os anciãos e os escribas. (...) E, levantando-se alguns, testificaram falsamente contra ele, dizendo: Nós ouvimos-lhe dizer: Eu derrubarei este templo, construído por mãos de homens, e em três dias edificarei outro, não feito por mãos de homens. E nem assim o seu testemunho era coerente. E, levantando-se o sumo sacerdote no Sinédrio, perguntou a Jesus, dizendo: Nada respondes? Que testificam estes contra ti? Mas ele calou-se, e nada respondeu. O sumo sacerdote lhe tornou a perguntar, e disse-lhe: És tu o Cristo, Filho do Deus Bendito. E Jesus disse-lhe: Eu o sou, e vereis o Filho do homem assentado à direita do poder de Deus, e vindo sobre as nuvens do céu. E o sumo sacerdote, rasgando as suas vestes, disse: Para que necessitamos de mais testemunhas Vós ouvistes a blasfêmia; que vos parece? E todos o consideraram culpado de morte." (Marcos 14: 53 e 57-64) 
Lucas: E logo que foi dia ajuntaram-se os anciãos do povo, e os principais dos sacerdotes e os escribas, e o conduziram ao seu concilio, e lhe perguntaram:

És tu o Cristo? Dize-no-lo. Ele replicou: Se vo-lo disser, não o crereis. E também, se vos perguntar, não me respondereis, nem me soltareis. Desde agora o Filho do homem se assentará à direita do poder de Deus. E disseram todos: Logo, és tu o Filho de Deus? E ele lhes disse: Vós dizeis que eu sou. Então disseram: De que mais testemunho necessitamos? pois nós mesmos o ouvimos da sua boca. Lucas 22:66-71

Observe-se que nos relatos de Mateus e Lucas ${ }^{9}$, em vez da formulação de outra pergunta no lugar da resposta, há, da parte de Jesus, uma derivação lógica, partindo-se do princípio de que a pergunta implica uma afirmação. A decisão do Grande Sacerdote de dispensar as testemunhas também decorre de derivação lógica, na medida em que devolve a implicação afirmativa para o enunciado proferido por Jesus: "Tu o disseste." "Vós dizeis que eu sou." Já em Marcos, há relato de resposta afirmativa, antecedida, porém, por um intervalo de silêncio.

Do Conselho Superior, Jesus é levado à presença de Pôncio Pilatos, governador romano. Trata-se da dimensão civil do julgamento, que se dá no pretório ${ }^{10}$, na residência do governador. Tudo indica que, para a condenação, não bastava o veredicto do segmento religioso, era preciso, também, a anuência do Estado. E diante de Pilatos, a estratégia da resposta implicatura volta à cena:

"Aí Pilatos perguntou a Jesus: - Você é o rei dos judeus? Jesus respondeu: -Tu o dizes." ( Mateus 27:11, Marcos 15:2, Lucas 23:3).

Se considerarmos que uma pergunta abre para resposta tanto afirmativa quanto negativa, teremos que a convocação da implicatura na pergunta justifica-se não somente por uma razão lógica, de conteúdo proposicional implicado, mas principalmente porque ela implica conteúdo assertado em outro lugar, antes e independentemente (o pré-construído), e que se lhe atravessa, marcando presença. Presença conflitante, é certo, e cujo embate é posto em evidência no diálogo ora apresentado. Observe-se parte do diálogo que antecedeu este segmento, no relato de João:

"Pilatos tornou a entrar no palácio, chamou Jesus e perguntou: - Você é o rei dos judeus? Jesus respondeu: - Esta pergunta é tua, ou outros falaram a meu respeito?" (João 18:33-34).

A ordem do boato", do "estão dizendo por aí" materializa-se enquanto discurso-transverso, cujo funcionamento, para Pêcheux (1988, p. 166), "remete àquilo que, classicamente, é designado por metonímia, enquanto relação da parte com o todo, da causa com o efeito, do sintoma com o que ele designa etc.”. Podemos pensar no efeito metonímico como a verdade por alguns reconhecida e que, ao encontrar-se implicada na pergunta de Pilatos, põe em cena o efeito de universalidade da assertiva subjacente - "Jesus é o rei dos judeus"- . É para isso que aponta a devolução de Jesus ao questionar se a pergunta deriva de afirmações de terceiros. O discurso transverso materializa, portanto, dizeres sobre Jesus que afirmariam sua autoridade, o que se coloca em posição antagônica ao objeto do julgamento. Encontra-se estabelecido um jogo de forças, no qual Pilatos chama Jesus à responsabilização acerca do que é acusado, num esforço para que Jesus adentre o lugar da "estranha evidência" dos sentidos, ao mesmo tempo em que Jesus recorre à(s) voz(es) do(s) outro(s) para legitimar seu lugar e papel. Ao mesmo tempo, a estratégia da

9 No Evangelho de João, não há o relato dessa segunda etapa da inquirição.

10 Local da residência do governador romano em Jerusalém.

11 A noção de boato será trabalhada na sequência do estudo. 
resposta-pergunta constitui-se construção que pode ser lida como um chamado à inscrição do sujeito que pergunta, diante da colocação em tela, por ele mesmo, de duas ordens de saberes distintas. Pilatos tenta eximir-se da inscrição, e também circunscreve responsabilidades para a acusação em cena, replicando-lhe:

"Por acaso eu sou judeu? A sua própria gente e os chefes dos sacerdotes é que o entregaram a mim. O que foi que você fez?" (v. 35)".

Jesus treplica, respondendo: "O meu Reino não é deste mundo. Se fosse, os meus servos lutariam para impedir que os judeus me prendessem. Mas agora o meu Reino não é daqui" (v.36).

\section{A pergunta como instauração de silêncios e lacunas significantes}

Se concebermos a pergunta em sua dimensão gramatical, qual seja, a estrutura de interrogação direta, marcada por um sinal específico, podemos focar o âmbito da pontuação como pista para perceber os processos discursivos manifestos no par pergunta-resposta. Para tanto, recorremos a Orlandi (2008), em estudo que autora faz acerca da pontuação, no qual ela defende, como premissa maior, que "as marcas de pontuação podem ser consideradas como manifestação da incompletude na linguagem, fazendo intervir em sua análise tanto o sujeito quanto o sentido" (p. 110). Tal se dá, segundo a autora, porque "a pontuação faz parte da marcação do ritmo entre o dizer e o não-dizer" (p. 111). O não-dizer, explicitado mais adiante por ela como o silêncio constitutivo, o que poderia ter sido dito e não o foi, podendo estar no campo do a-dizer, ou como dizer interditado, integra o domínio do interdiscurso na textualização do discurso.

Situando a reflexão acerca da pontuação na perspectiva do par acréscimo (incisa) e falta (elipse), a autora explicita a pontuação como acréscimo que "põe em funcionamento os mecanismos de ajuste imaginário entre o discurso e o texto, pondo em jogo a dimensão simbólica do sujeito" (p. 112). Isso nos leva a nos perguntarmos sobre por que discurso e texto estariam, supostamente, em desajuste. A autora nos responde que a sempre possibilidade dos sentidos múltiplos atesta esse espaço difuso, essa distância não preenchida, manifestação, portanto, do processo de subjetivação. A pontuação funciona, portanto, como lugar de amarra, de vestígios da articulação do sujeito a um discurso e sua inscrição em uma formação discursiva (p. 113).

Essa necessidade de ajuste, pautada por Orlandi como indicativa de lugar de inscrição do sujeito, leva-nos a trazer para a discussão a noção de ajustamento, apontada por Gadet ${ }^{12}$ como fenômeno enunciativo manifesto na relação questão-resposta numa interrogação e explicitada por Pêcheux (1988, p. 193) como ajustamento de um discurso a si mesmo enquanto estabelecimento como verdade, "de modo que a própria estrutura da forma-sujeito com a relação circular sujeito/objeto se torna o "limite" visível do processo."

Esta noção é produtiva para pensarmos o funcionamento discursivo das diferentes relações que se estabelecem entre a pergunta e a resposta do modo como são colocadas no discurso em tela. Inicialmente, há a relação estabelecida entre a formulação de Pilatos e o espaço inaugurado para a(s) resposta(s) de Jesus. Conforme defendemos em Rasia (2013), “o ajuste dá-se, em nosso entendimento, no ponto de encontro entre o efeito de indeterminação e a circunscrição a um determinado conjunto de saberes ou a uma determinada construção identitária."

12 "Uma relação fundamental com a língua", in: PIOVEZANI, Carlos e SARGENTINI, Vanice. Legados de Michel Pêcheux. São Paulo: Contexto, 2011. 
Na formulação de Pilatos a Jesus há o efeito de abertura, de indeterminação que chama à circunscrição, dimensão essa tecida pela resposta, visto que nela se produz o efeito de fechamento, e o liame entre a abertura e o fechamento é graficamente tecido pelo ponto de interrogação. Já no caso da resposta na forma de pergunta, tal como formulada por Jesus, o efeito de fechamento não se dá, pois mantêm-se os pontos de fuga, de vazão dos sentidos, restando o chamado à circunscrição aparentemente obliterado.

\section{A pergunta e a relação com o boato}

Outra dimensão a ser considerada na análise em tela diz respeito à convocação, pela pergunta de Pilatos, do âmbito do boato, na inquirição a Jesus. Essa dimensão sustenta-se pelo modo como evolui o jogo pergunta-resposta, essencialmente pelo esforço empreendido com vistas ao preenchimento das lacunas. Definido por Orlandi (2008, p. 134) como "notícia anônima que se expande publicamente sem confirmação, um modo de dizer em que há sempre uma diferença a significar, um ruído (protesto ou falta de verdade)", o boato não está, nessa perspectiva, pautado pela disputa verdade x mentira, mas situado em uma ordem política do dizer, um fato da linguagem pública, um modo de circulação das palavras.

$\mathrm{O}$ formato pergunta-resposta, que configura o modo como Jesus responde à interpelação de Pilatos, segundo o relato que conta no evangelho de João, conforme já referido, implica o "diz-se-que" da boataria, a indeterminação do "dizem por aí". Modo esse de circulação da palavra que comporta, simultaneamente, efeito de falsidade e de verdade: se não há uma autoria atestada, provavelmente é mentira. Por outro lado, se o boato subsiste enquanto fato de linguagem, podendo, inclusive, submeter sujeitos ao confronto, tal como Jesus faz com Pilatos, é possível de ser inscrito no âmbito da veracidade. Configura-se, segundo Orlandi (op.cit., p. 131), como "fato relevante para se observar essa faixa do dizer que está entre o atestado e o possível.” Nisso consiste a colocação da tomada da palavra na ordem do equívoco, ainda nos termos de Orlandi.

Esse situar-se no espaço limítrofe entre verdade e falsidade é bastante significativo no caso da discursividade que funda o Cristianismo. Atentemos para os relatos de milagres de Jesus, na maior parte dos quais, o Mestre pede aos discípulos, seguidores e beneficiados, que "não contem a ninguém", "Que não espalhem a notícia13". A injunção ao silêncio pode significar de modos distintos: pode se tratar de estratégia de auto-proteção, resultado da ameaça que Jesus sabia representar às autoridades instituídas, se espalhada sua popularidade; ou pode se tratar de uma estratégia de produção do dizer: "Conhecer, controlar e fazer circularem os boatos são uma forma de poder”, segundo Amado (1998), apud Orlandi (2008).

Nos registros de Mateus, Marcos e Lucas, a resposta à pergunta : “- Tu o dizes.”, além do chamamento do sujeito que diz à inscrição, conforme já referido, funciona também como espaço que dá vida e visibilidade à ordem do boato, dando-o ao conhecimento em uma instância de poder e, acima de tudo, controlando-o, porque chamando à assinatura da autoria, e com isso gerando as condições necessárias para a produção da legitimidade.

Ainda com base em Orlandi (2008), a função-autor configura-se como lugar de legitimação do texto, posto que o coloca sob o prisma da responsabilização e, no caso do boato, dilui o caráter de comentário. Por essa razão, sublinha a autora, o boato tende a evitar o confronto direto. No caso da inquirição de Jesus, como vimos, há, por parte deste, um

13 Conforme Mateus 8:4; 9:30; 12:16, por exemplo. 
reclame pela responsabilização, um esforço no sentido de mudar-se o estatuto das afirmações acerca de sua pessoa. Não por acaso, Pilatos pergunta a Jesus “- O que é a verdade?”, após insistir na inquirição: “- Então você é o rei?” e ser mais uma vez confrontado por Jesus: “- É o senhor que está dizendo que eu sou rei! Foi para falar da verdade que eu nasci e vim ao mundo. Quem está do lado da verdade ouve a minha voz" (João 18:37-38).

A hermenêutica de cunho teológico colhe, dessa passagem, os fundamentos da fé cristã; contudo, não dá para deixar de ver o lugar de dissenso que se instaura, pela voz do próprio Cristo, diga-se de passagem. Dissenso que, ao mesmo tempo em que joga a esfera para a ordem da indeterminação, joga com um esforço de circunscrição. Eis o equívoco, eis o lugar de subjetivação via assinatura dos sujeitos em uma ordem de saber. Livres para se submeterem.

\section{Algumas Considerações Finais}

O par pergunta-resposta implica sempre jogo, não necessariamente com vencedor e derrotado, mas enquanto construção do que talvez se possa chamar de "consenso". Essencialmente porque a pergunta pode partir do pressuposto do dissenso resultante da inscrição em diferentes lugares. Nesse caso, a colocação em cena da pergunta pode ter como direcionamento a chamada à resposta passível de deslocar o lugar do dissenso para o do consenso, tendo em vista o enquadramento da pergunta dentro de uma determinada FD. Ou, ao contrário, pode estar constituindo lugar de visibilidade para a diferença, com justificativa da ruptura.

No caso em tela, no qual a própria resposta assume a forma interrogativa, delineia-se um lugar de convocação da voz do outro na voz do um, ou, em outras palavras, a produção de um ponto de convergência entre posições-sujeito antagônicas (a dos seguidores de Jesus e a de seus adversários).

A pergunta emblemática feita por Pilatos “- O que é a verdade?” - reporta à noção de condição de verdade, que, neste caso, extrapola a restrição às construções do modo indicativo, as assertivas de conteúdo proposicional. Tal se dá porque a significação da frase interrogativa pode ser identificada a partir de suas condições de resposta, ou seja, saber o que uma frase interrogativa significa reporta a saber aquilo que conta, e em quais circunstâncias, como uma resposta verdadeira. Ora, o espaço da resposta figuraria, em tese, como estabelecimento das circunstâncias em relação à pergunta. $\mathrm{O}$ modo como se constitui a enunciação de Jesus, jogando a resposta para o campo da abertura, via nova interrogativa, com jogo de implicaturas, deixa em aberto o espaço do circunstancial, o qual, em nosso entendimento, possibilita que se teça o liame entre subjetivação e história. É este o lugar das amarras, dos nós que se estabelecem não sem tensionamento, lugar emblemático onde o sujeito se move por entre o paradoxo da singularização não-subjetiva própria dos processos históricos de determinação.

\section{Referências}

BÍBLIA DE ESTUDO ALMEIDA. Barueri, SP: Sociedade Bíblica do Brasil, 1999. BÍBLIA NOVA VERSÃO INTERNACIONAL. Disponível em : www.bibliaonline.com. br/ (acesso em 15/07/12).

DAVIDSON, F. et.all. O novo comentário da Bíblia. São Paulo: Vida Nova, 1997. 
DOCKERY, David. Manual bíblico vida nova. São Paulo: Vida Nova, 2001.

EAGLETON, Terry. Jesus Cristo: os evangelhos. Rio de Janeiro: Jorge Zahar, 2009.

GADET, F. "Uma relação fundamental com a língua", in: PIOVEZANI, Carlos e SARGENTINI, Vanice. Legados de Michel Pêcheux. São Paulo: Contexto, 2011.

JOHNSON, Paul. Jesus: uma biografia de Jesus Cristo para o século XXI. Rio de Janeiro: Nova Fronteira, 2011.

ORLANDI, Eni P. (org.) Discurso fundador. Campinas, S. P: Pontes, 1993.

. Discurso e texto: formulação e circulação dos sentidos. São Paulo: Pontes, 2001.

PÊCHEUX, Michel. Semântica e discurso. Ed. da Unicamp, 1988.

RASIA, Gesualda. "A pergunta como espaço de (in)determinação". (no prelo). 